\title{
EIIIA
}

Revista Eletrônica de Estudos Integrados em Discurso e Argumentação

\section{A ARGUMENTAÇÃO RETÓRICA NO GÊNERO FÍLIMICO DOCUMENTAL}

Fábio Ávila Arcanjo ${ }^{\mathrm{i}}$

Resumo: O presente artigo visa discutir os pontos de contato existentes entre o gênero documentário e a argumentação retórica. Buscaremos dissertar acerca da presença de algumas categorias originárias da Análise Argumentativa do Discurso, que operou uma releitura da chamada retórica aristotélica, no trabalho discursivo realizado pelo documentarista. Nossa análise se baseará em apreciar esse gênero fílmico mediante três pressupostos: gêneros da retórica - demonstrativo, deliberativo e judiciário; partes do discurso - concernente ao que o filósofo belga Michel Meyer (2007) nomeia de edifício retórico (invenção, disposição, elocução, ação e memória); e provas retóricas - éthos, lógos e pathos. Além dessas questões, iremos discutir o posicionamento de certos documentários na dicotomia dimensão argumentativa $x$ intenção argumentativa proposta pela pesquisadora francesa Ruth Amossy (2011). As análises presentes nesse artigo são oriundas de um recorte da nossa pesquisa de mestrado. Nesse sentido, utilizaremos como corpus alguns documentários nacionais e internacionais.

Palavras-chave: Documentário. Argumentação. Retórica. Adesão.

Abstract: This article aims to discuss the points of contact between documentary film genre and rhetorical argumentation. We are going to talk about the presence of some categories originated from the Argumentative Discourse Analysis, which operated an interpretation of aristotelian rhetoric, in the discursive work done by the documentarist. Our analysis will be based on appreciating this filmmaking gender in three assumptions: genres of rhetoric - demonstrative, deliberative and judicial -; parts of the speech - concerning what the belgian philosopher Michel Meyer (2007) names as rhetorical building (invention, disposition, elocution, action and memory) -; and rhetorical evidences - éthos, lógos and pathos. We are going to discuss about the positioning documentaries in the dichotomy: argumentative dimension $x$ argumentative intention on the french research Ruth Amossy (2011). The analysis of this article comes from a clipping of our master's research. We will use as corpus some national and international documentaries.

Keywords: Documentary. Argumentation. Rhetoric. Adhesion.

i Doutorando pelo Programa de Pós-Graduação em Estudos Linguísticos da Universidade Federal de Minas Gerais (UFMG). E-mail: fabioarcanjo1981@hotmail.com. 
EID\&A - Revista Eletrônica de Estudos Integrados em Discurso e Argumentação, Ilhéus, n. 13, jan/jun.2017.

\section{Introdução}

Pensar o documentário como fruto de uma atividade retórica implica na percepção de algumas categorias que se apresentam marcantes no modo de organização desse tipo de discurso fílmico. A saber: persuasão, adesão e argumentação. É interessante destacar que o cinema, já no início, solidificou-se mediante um desmembramento genérico. $O$ que se quer dizer com isso? $O$ fato é que se elencarmos nomes importantes para a consolidação da linguagem cinematográfica, como Georges Méliès e Auguste e Louis Lumière, veremos que o primeiro se inscreve no cinema ficcional, enquanto os irmãos franceses poderiam ser considerados precursores do registro documental. No tocante a esse ponto, Marcel Martin (2013, p. 15) afirma:

Lumière não tinha consciência de fazer uma obra artística, mas simplesmente de reproduzir a realidade: no entanto, vistos em nossos dias, seus pequenos filmes são fotogênicos. O caráter quase mágico da imagem cinematográfica aparece então com toda a clareza: a câmera cria algo mais que uma simples duplicação da realidade

Ao afirmar o papel criador da câmera, Martin assevera que existe um projeto de fala, ou seja, essa criação é originária daquilo que Bill Nichols (2014) nomeia sujeito-da-câmera ${ }^{1}$. Diante disso, nos parece conveniente analisar o item lexical realidade, pois ele nos remete à clássica definição de documentário conferida pelo produtor inglês John Grierson (1979). Ele afirma que esse tipo de gênero fílmico tem como leitmotiv a confecção de um tratamento criativo da realidade. O termo criativo chama a nossa atenção, pois ele nos direciona para a observação conferida por Martin acerca da criação operada pela câmera, que, vale dizer, é um dos principais componentes do trabalho de discursivização operado pelo sujeito-da-câmera.

Vamos, portanto, ao ponto. O que nos interessa, justamente, é esse processo criativo, ou seja, o presente artigo volta o olhar para a figura do documentarista, que, ao iniciar o processo de enunciação fílmica, cria para si uma imagem. A respeito da retoricidade do gênero em questão, podemos convocar o dizer de Bill Nichols (2014), pois ele estabelece uma asserção que nos parece fundamental.

A voz do documentário é, com muita frequência, a voz da oratória. É a voz do cineasta que tenciona assumir uma posição a respeito de um aspecto do mundo histórico e convencer-nos de seus méritos. Essa posição trata de aspectos do

\footnotetext{
${ }^{1}$ Nomenclatura associada à figura do documentarista.
} 
EID\&A - Revista Eletrônica de Estudos Integrados em Discurso e Argumentação, Ilhéus, n. 13, jan/jun.2017.

mundo sujeitos a discussão, de questões e tópicos que não se prestam à investigação científica. Como questões de compreensão, interpretação, valor e julgamento sobre o mundo em que realmente vivemos, elas requerem uma forma de falar fundamentalmente diferente da lógica ou da narração de histórias. A tradição retórica propicia uma base para essa maneira de falar (NICHOLS, 2014, p. 79 e 80).

O que se pode depreender do fragmento anterior é que, de alguma forma, o documentarista procura obter a adesão do público para a "realidade" que será transmitida. É importante destacar que a busca por essa adesão poderá, ou não, ser mais enfática, dependendo do modo de organização escolhido pelo cineasta. Discutiremos isso ao longo de nosso texto. $O$ ponto que nos parece relevante destacar é que o discurso fílmico documental transmite um recorte subjetivo da realidade.

Enquadrar o discurso fílmico documental como uma atividade retórica implica na problematização de categorias que se mostram fulcrais para a interface objetivada por nosso artigo. A saber: gêneros da retórica (demonstrativo, deliberativo e judiciário), que, conforme poderá ser atestado, serão analisados mediante um arranjo metodológico, pois o cinema documental se diferencia da utilização canônica de tais gêneros; edifício retórico (invenção, disposição, elocução, ação e memória), em que analisaremos a estruturação dos documentários; e as provas retóricas (éthos, lógos e pathos), que consistem nas construções das imagens de si, aliadas às emoções e aos raciocínios implicados na organização fílmica.

O artigo será dividido em três partes. Na primeira, discutiremos a dinâmica existe entre os sujeitos do discurso fílmico documental. Para tanto, dois conceitos serão importantes no desenvolvimento do tópico: auto-miseen-scène e performance. A segunda parte, mais extensa, primará em lidar com as categorias discriminadas no parágrafo anterior. Por fim, faremos uma discussão a respeito das fronteiras existentes entre a dimensão argumentativa e a intenção argumentativa. Com a finalidade de ilustrar os apontamentos, utilizaremos alguns documentários, como, por exemplo, Estamira (2005) adotado como corpus principal da nossa dissertação de mestrado -, além de outras produções igualmente presentes na dissertação citada.

\section{Os sujeitos do discurso fílmico documental}

A partir da definição que encerra a introdução faz-se necessário focar na atuação dos sujeitos do discurso fílmico documental, pois o item lexical subjetivo, 
EID\&A - Revista Eletrônica de Estudos Integrados em Discurso e Argumentação, Ilhéus, n. 13, jan/jun.2017.

pensando em nosso lugar de fala, precisa ser mais bem discutido. $O$ pesquisador e cineasta Jean-Louis Comolli (2008) poderá nos ajudar nessa questão:

Colocar em cena é ser colocado em cena. É ser colocado na cena pela própria constituição de uma cena. Aquele (a) que eu filmo me olha. O que ele (ela) olha ao me olhar é o meu olhar (escuta) para ele (ela). Olhando o meu olhar, isto é, uma das formas perceptíveis de minha mise-en-scène, ele (ela) me devolve no seu olhar o eco do meu, retorna minha mise-en-scène tal como repercutiu nele (nela). (COMOLLI, 2008, p. 82).

A partir do excerto anterior, é possível compreender o principal mecanismo enaltecido pelo teórico francês: troca comunicacional. Nesse sentido, o discurso fílmico documental é fundamentado mediante um processo de interação, porém, precisamos salientar que não se trata de um processo simétrico, uma vez que o sujeito-da-câmera é o detentor do chamado corte final, ou seja, ele é o responsável pela organização do material filmado, através da montagem².

A pergunta mais pertinente ao tema de nossa discussão é: como se dá o funcionamento do processo de construção das imagens? Podemos considerar essa questão como sendo uma espécie de jogo etótico, no sentido em que há uma troca, e por que não dizer, um gerenciamento imagético. $O$ documentarista, ao colocar em cena uma determinada narrativa, cria para si uma imagem, ou seja, ele projeta éthos discursivos. Ao mesmo tempo, dependendo do espaço disponibilizado por esse cineasta, há, também, a construção da imagem do ator social 3. Podemos justificar essa asserção a partir do documentário Estamira ${ }^{4}$, analisado em nossa dissertação de mestrado.

A imagem do diretor de Estamira - Marcos Prado - sofre um tipo de desdobramento, no sentido de que há um efeito duplo, que parece possuir uma carga antitética. Em primeiro lugar, ele constrói para si uma imagem de generosidade. Como isso se dá? Jean-Louis Comolli adota um conceito para o estudo de obras fílmicas documentais. Estamos falando da retirada estética,

\footnotetext{
2 "A definição técnica da montagem é simples: trata-se de colar uns após os outros, em uma ordem determinada, fragmentos de filme, os planos, cujo comprimento foi igualmente determinado de antemão" (AUMONT, 2013, p. 195).

3 Nomenclatura utilizada para definir os entrevistados (as).

4 ESTAMIRA. Dir. Marcos Prado. Documentário. Brasil: Vinny Filmes, 2005. 116 min., cor. A produção narra a trajetória da personagem homônima, que sobrevive em condições sub-humanas no extinto lixão Jardim Gramacho, localizado no estado do Rio de Janeiro. Em meio ao caos reinante naquele lugar, nossa personagem realiza divagações de cunho existencial. $O$ filme se estrutura a partir das falas de Estamira - que, diga-se de passagem, foram mantidas sem cortes na montagem - e de entrevistas com os familiares dela.
} 
EID\&A - Revista Eletrônica de Estudos Integrados em Discurso e Argumentação, Ilhéus, n. 13, jan/jun.2017.

que seria um recolhimento da voz do documentarista. Diante disso, há um recuo, um afastamento, que pode culminar, ou não, dependendo da intencionalidade do diretor, na amplificação da voz do ator social. Nesse sentido, podemos trazer para nossa discussão o conceito de auto-mise-scène ${ }^{5}$, resultado dessa retirada estética. O que o sujeito Marcos Prado proporciona é um espaço de inscrição da personagem, ou seja, ele opera uma retirada estética para que Estamira possa construir a auto-mise-scène. Ao mesmo tempo, Prado constrói uma imagem de refinamento, um éthos de vanguardista. Os elementos que tornam possíveis essa percepção são: uso diversificado da fotografia, que alterna o preto e branco com o colorido; utilização de trilha sonora marcante, que pontua a obra em diversos momentos; emprego de variados tipos de planos ${ }^{6}$; utilização de inúmeras metáforas visuais 7 através da montagem; entre outros. O que se pode afirmar é que o documentário possui uma intensa força enunciativa ${ }^{8}$, oriunda da performatividade.

Mencionamos o éthos do sujeito Marcos Prado, no entanto, sem alongar muito a discussão, é interessante apresentar o éthos do sujeito Estamira, que se manifesta a partir de suas performances 9 . Faz-se necessário tratar a performatividade como sendo um movimento de fabulação, ou seja, o ator social opera reinvenções de si, que são motivadas pelo espaço de inscrição proporcionado pelo documentarista. Em Estamira, há a incursão de três tipos de performances: Xamanística/educativa - a personagem constrói para si uma

\footnotetext{
${ }^{5}$ Duplo processo de individuação que acontece no ato da enunciação fílmica. Esse mecanismo se dá mediante os elementos dóxicos que permeiam a vida do ator social, ou seja, os valores, crenças e experiências adquiridas ao longo de sua vida - isso seria um elemento externo ao processo fílmico, mas que se inscreve na interação - e da troca comunicacional construída entre o ator social e o sujeito-da-câmera - componente interno da enunciação fílmica. (COMOLLI, 2008).

6 "O tamanho do plano (e consequentemente seu nome e seu lugar na nomenclatura técnica) é determinado pela distância entre a câmera e o objeto e pela duração da cena utilizada" (MARTIN, 2013, p. 39).

7 Em vários momentos, a figura de Estamira é metaforizada como sendo uma força da natureza. Em proferimentos mais agressivos, sua imagem é associada a elementos naturais, como o relâmpago e o trovão. Em outros, mais suaves, ela é vinculada ao mar.

8 A dobra no processo de construção da imagem de si manifesta-se, consequentemente, na performatividade, uma vez que esta última se encontra atrelada ao éthos. Não é apenas Estamira que realiza performances, pois o documentarista, mediante diversas escolhas estratégicas mencionadas ao longo do texto, também performa a sua mise-en-scène. Estamira realiza reinvenções de si, ou seja, ela fabula a sua vida, ao passo que o sujeito Marcos Prado opera reinvenções de sua enunciação fílmica, lembrando que este cineasta possui uma carreira de sucesso como fotógrafo. Não se pode desconsiderar que a trajetória pregressa de Prado encontra ressonância na presente obra.

9 Para o pesquisador André Brasil (2011, p. 10), a performance é um "processo de alienação: momento em que me alieno de mim mesmo, tornando-me outro. Ele é, precisamente, o encontro do ser com aquilo que o ultrapassa".
} 
EID\&A - Revista Eletrônica de Estudos Integrados em Discurso e Argumentação, Ilhéus, n. 13, jan/jun.2017.

imagem de líder espiritual -; Encolerizada - aqui, ela se reveste da imagem de justiceira social, que utiliza da cólera ${ }^{10}$ para manifestar seu descontentamento frente à desigualdade social -; Melodramática - os elementos dóxicos, em tais performances, se apresentam proeminentes. Conhecemos, nesses momentos, as terríveis experiências de vida enfrentadas por Estamira.

Fechamos nossa discussão sobre a subjetividade trazendo um importante postulado da Análise do Discurso, campo do saber que constitui o nosso lugar de fala. Postulamos que as produções do gênero documentário, a exemplo de outros tipos de manifestações artísticas, se inscrevem em um interdiscurso, ou seja, pontos de vista colocados em cena por determinados cineastas emergem em um domínio atravessado por diversos discursos. Há um passado que emerge no presente, que, de certa forma, influencia aquilo que é contemporâneo. Ao mesmo tempo, o atual influenciará o futuro. Pensemos em um caso emblemático: o holocausto nazista. Podemos trazer três discursos fílmicos documentais que lidaram com esse tema, em um recorte de tempo diferente. Noite e neblina (1955), cujo diretor Alain Resnais tem acesso aos campos de concentração, e registra essas imagens em forma de discurso fílmico, se valendo, predominantemente, de imagens de arquivo. Shoah (1985) retrata a "saga" do diretor francês Claude Lanzzman em busca de sobreviventes da barbárie. Aqui, ao contrário do anterior, não há imagens de arquivo, mas, sim, inúmeras entrevistas. Paragraph 175 (2000), dirigido por Rob Epstein e Jeffrey Friedman, parte da mesma premissa de Shoah, mas o alvo, nesse caso, são sobreviventes homossexuais.

Além do interdiscurso, outro elemento constitutivo do discurso fílmico documental é a argumentatividade. Christian Plantin (2011, p. 17) afirma que "uma dada situação linguageira começa a se tornar argumentativa [e retórica] quando manifesta uma oposição de discursos". Ruth Amossy (2011, p. 129), por seu turno, afirma que "toda troca verbal repousa sobre um jogo de influências mútuas e sobre a tentativa, mais ou menos consciente e reconhecida, de usar a fala para agir sobre o outro". Embora sejam perspectivas distintas, podemos inferir que a oposição de discursos observada por Plantin - e o jogo de influências mútuas - postulada por Amossy - estão no cerne do trabalho desenvolvido pelos documentaristas. Diante disso, podemos afirmar que um documentário pode contra-argumentar uma

${ }^{10}$ De acordo com Michel Meyer (2000, p. 43), "a cólera é um brado contra a diferença imposta, injusta ou como tal sentida". Ele ainda afirma que ela "reequilibra a relação proveniente do ultraje, da afronta, do desprezo" (Ibidem). 
EID\&A - Revista Eletrônica de Estudos Integrados em Discurso e Argumentação, Ilhéus, n. 13, jan/jun.2017.

linha de pensamento, ou seja, ele pode se opor a um tipo de discurso. E, também, pode influenciar na apresentação de um determinado ponto de vista, podendo obter, com isso, algum tipo de adesão junto ao sujeitoespectador.

\section{A organização retórica do gênero documentário}

A primeira questão a ser enfatizada no presente tópico é a aplicabilidade dos gêneros da retórica na organização do discurso fílmico documental. Os componentes de tais gêneros são: demonstrativo/epidítico, deliberativo e judiciário. É possível perceber a presença de uma, ou mais, dessas categorias nos documentários produzidos ao longo da história. Tentemos citar alguns exemplos significativos: no caso do demonstrativo, é de fácil percepção, uma vez que produções organizadas a partir do gênero epidítico, de alguma forma, seriam motivadas a prestar algum tipo de homenagem a determinadas pessoas, que podem, ou não, serem públicas. Casos profícuos podem ser encontrados nos documentários biográficos, embora, não necessariamente, eles sejam impulsionados a homenagear alguém. Mas, indo ao encontro do nosso objetivo, podemos citar o filme Maradona by Kusturica (2008), dirigido pelo sérvio Emir Kusturica. O filme é uma ode ao ex-jogador de futebol. Através dele, temos acesso à intimidade do atleta argentino, sendo possível perceber a admiração que o cineasta nutre por ele.

Para o gênero deliberativo é preciso fazer um arranjo, pois, como sabemos, o documentário não formula e promulga leis. Como fazer para aplicar as características do gênero no discurso fílmico documental? A resposta pode ser alcançada por meio da análise de produções que procuram apresentar algum tipo de resposta para determinados problemas ou situações. $O$ modo de organização"1 mais adequado para obras fílmicas desse tipo seria o expositivo, que segundo Bill Nichols (2014, p. 142), "agrupa fragmentos do mundo histórico numa estrutura mais retórica do que estética ou poética. [...] dirige-se ao espectador diretamente". Exemplos podem ser

\footnotetext{
1 São seis os modos de organização observados por Bill Nichols: poético, observativo, expositivo, participativo, reflexivo e performático. É válido indicar que o documentário problematizado em nossa dissertação de mestrado - Estamira -, a nosso ver, se inscreve na última categoria. Para mais informações sobre esses modos, sugerimos a leitura de Introdução ao documentário (NICHOLS, 2014, p. 138-171).
} 
EID\&A - Revista Eletrônica de Estudos Integrados em Discurso e Argumentação, Ilhéus, n. 13, jan/jun.2017.

encontrados nas produções da Caravana Farkas ${ }^{12}$ e nos documentários brasileiros dos anos 1960 e 1970, cujos documentaristas buscavam ditar algumas regras a partir de uma visada notadamente engajada politicamente.

O gênero judiciário, por sua vez, também necessita de um arranjo. Como refletir a respeito da justiça, imiscuída no discurso fílmico documental? Uma resposta possível gira em torno da possibilidade de operar uma espécie de "acerto de contas" com um passado traumatizante. Existem diversas produções que têm como objetivo aparar as arestas que, por ventura, tenham sido deixadas abertas em função de uma experiência de vida ainda não cicatrizada. Citemos alguns exemplos interessantes: S21 - a máquina de morte do Khmer vermelho (2003), dirigido pelo Cambojano Rithy Pahn, que opera uma rememoração dos horrores cometidos pelo governo ditatorial de Pol Pot; Ato de matar (2012), de Joshua Oppenheimer, em que o diretor convoca os antigos executores do genocídio cometido nos anos 1960, pelo governo tailandês vigente naquela época, para recriar os rituais de tortura e assassinato cometidos contra os opositores do regime; e Retratos de identificação (2014), no qual sua diretora - Anita Leandro - realiza uma mescla de imagens de arquivo com depoimentos de dois militantes (Antônio Roberto Espinosa e Reinaldo Guarany) contrários à ditadura militar, que vigorou no Brasil entre os anos 1960 e 1980.

A próxima questão a ser problematizada nesse tópico gira em torno das chamadas partes do discurso, agrupadas pelo filósofo Michel Meyer (2007) em um edifício retórico, composto por cinco "andares": invenção, disposição, elocução, ação e memória. Faremos, a seguir, uma discussão resumida a respeito dessas categorias.

A invenção seria o primeiro estágio de organização do discurso fílmico. $O$ item lexical pode causar um estranhamento, uma vez que somos amparados pela Análise do Discurso. Porém, evocando Ruth Amossy (2013), a invenção poderia ser construída mediante a atuação de uma "bagagem dóxica". Ao transmitir determinados pontos de vista, o documentarista se municia de argumentos que são encontrados nos topoi'3 (lugares). A disposição é,

\footnotetext{
12 Série de curtas metragens, produzidos entre as décadas de 1960 a 1980, que tinham como objetivo mostrar a realidade brasileira de uma forma "nua e crua". Segundo Meize Lucas (2012, p. 176), o projeto postulava um "papel educativo do cinema como elemento de formação da identidade nacional [...] e [tinha] uma forte preocupação em trazer para a tela a diversidade de falas do homem brasileiro".

${ }^{13}$ Olivier Reboul (2004, p. 51-52) aponta três sentidos para o conceito de lugar. O primeiro seria o "argumento pronto". O segundo postula que ele é um "tipo de argumento - lugar-comum -, um
} 
EID\&A - Revista Eletrônica de Estudos Integrados em Discurso e Argumentação, Ilhéus, n. 13, jan/jun.2017.

segundo Michel Meyer, o ápice do edifício retórico. Ela se inscreveria, no discurso fílmico documental, como sendo uma instrumentalização da montagem, ou seja, essa categoria participa da organização/discursivização do material filmado. É válido frisar que a montagem está atrelada ao roteiro, mesmo em documentários que apresentam "roteiros abertos", ou seja, que primem por certa indeterminação enunciativa, no sentido de não excluírem aquilo que poderia ser interpretado como contingente. Um caso significativo desse tipo de mise-en-scène é o cineasta brasileiro Eduardo Coutinho. Bill Nichols (2014, p. 89) afirma:

Todas as várias formas de subdivisão enfatizam uma alternância entre recursos à prova e recursos ao público, recursos ao fato e recursos à emoção. Uma vez que os assuntos tratados pela retórica sempre envolvem questões de valor e crença, bem como prova e fato, essa alternância faz sentido. Ela permite que o discurso, ou a voz do documentário, acrescente matéria aos fatos, localize os argumentos não no domínio abstrato da lógica impessoal, mas no domínio concreto da experiência personificada e da ocorrência histórica.

Portanto, é conveniente refletir nas subdivisões como sendo eixos temáticos que, por ventura, possam surgir ao longo da obra. A disposição pode ser dividida em quatro partes: exórdio - chamada de atenção; narração apresentação do ponto de vista; argumentação ou demonstração desenvolvimento, tácito ou explícito, do ponto de vista, através de estratégias que visam a adesão do público; e epílogo - conclusão das ideias apresentadas. Essa decomposição pode ser percebida em grande parte dos documentários, embora saibamos que eles podem apresentar diversos modos de organização. O que queremos dizer com isso? Certamente, os documentários marcadamente poéticos, por exemplo, suprimem algumas dessas divisões, embora isso também possa ocorrer em outros tipos de produções desse gênero.

A elocução está relacionada ao plano de expressão e, nesse sentido, é válido levar em consideração as estratégias fílmicas adotadas pelo sujeito-dacâmera. Fazem parte dessa categoria recursos como: utilização multifuncional da câmera (enquadramentos, tipos de planos, ângulos de filmagem e movimentos de câmera), fotografia, trilha sonora etc. Ressaltamos novamente a importância do papel da montagem nesse processo.

esquema que pode ganhar os conteúdos mais diversos". O terceiro, por sua vez, define que o lugar é "uma questão típica que possibilita encontrar argumentos e contra-argumentos". Uma pertinente definição para lugares foi dada por Roland Barthes em citação realizada pelo linguista brasileiro José Luiz Fiorin (2015): “Os lugares são, em princípio, formas vazias. Mas essas formas logo tiveram a tendência a se encher sempre do mesmo modo, a exprimir conteúdos, primeiro, contingentes, depois, repetidos e reificados" (BARTHES, 1975. p. 197 apud FIORIN, 2015, p. 95). 
EID\&A - Revista Eletrônica de Estudos Integrados em Discurso e Argumentação, Ilhéus, n. 13, jan/jun.2017.

Em algumas categorias, trabalhadas anteriormente, mencionamos a necessidade de estabelecer alguns arranjos para a aplicabilidade dos pressupostos da retórica na organização do discurso fílmico documental. Para lidar com a memória, faz-se novamente necessário efetuar uma adaptação, pois, na retórica clássica, a memória estava atrelada à espontaneidade dos proferimentos, ou seja, ela era utilizada no processo de enunciação, constituinte das interações. Nos documentários, temos um quadro diametralmente oposto, pois a enunciação se transforma em enunciado a partir do trabalho de montagem e pós-produção. Contudo, essa inadequação não nos impede de pensar no caráter memorialístico dos documentários. Bill Nichols nos fornece dois caminhos para construir esse arranjo: "Em primeiro lugar, o filme em si é um tangível teatro de memórias. É uma representação externa e visível do que foi dito e feito" (2014, p. 90). "Em segundo lugar, a memória é parte das várias maneiras como os espectadores se servem do que já viram para interpretar o que estão vendo" (ibid.). As duas asserções anteriores nos remetem à interdiscursividade e à heterogeneidade, constituintes dos discursos fílmicos documentais, uma vez que eles são organizados em meio aos, evocando Patrick Charaudeau (2013), imaginários sóciodiscursivos ${ }^{14}$.

A ação seria, citando novamente Bill Nichols, a voz do documentarista, ou seja, é aqui que a subjetividade se faz notar, não podendo desconsiderar os imaginários condicionantes, que originam o "jogo de projeções de imagens" arquitetado pelos sujeitos do discurso. Segundo Nichols (2014, p. 92), “a voz do documentário atesta seu engajamento numa ordem social e sua avaliação dos valores subjacentes a essa ordem. É a orientação específica para o mundo histórico que dá ao documentário sua voz própria”. Concluímos que a ação poderia ser pensada como sendo o processo de enunciação fílmica.

A última questão a ser tratada no presente tópico gira em torno das provas retóricas - éthos, lógos e pathos. Antes de refinarmos nossa tratativa, é preciso frisar que essas categorias se imiscuem no discurso fílmico, embora possa existir a proeminência de algumas delas em determinados documentários.

${ }^{14}$ Os imaginários sóciodiscursivos circulam, portanto, em um espaço de interdiscursividade. Eles dão testemunho das identidades coletivas, da percepção que os indivíduos e os grupos sociais têm dos acontecimentos, dos julgamentos que se fazem de suas atividades sociais. (CHARAUDEAU, 2013, p. 207). 
EID\&A - Revista Eletrônica de Estudos Integrados em Discurso e Argumentação, Ilhéus, n. 13, jan/jun.2017.

No tocante ao éthos, considerado pelo linguista Ekkehard Eggs (2013) como a mais importante prova engendrada pelo discurso, fizemos, anteriormente, uma discussão, tendo como ponto de partida o documentário problematizado em nossa dissertação de mestrado. Mencionamos o jogo de imagens "disputado" entre os sujeitos do discurso fílmico documental, no sentido de que o documentarista, ao organizar a obra, cria para si uma imagem, podendo, ou não, abrir um espaço de inscrição para que o ator social do filme possa gerenciar, também, a própria imagem. Meyer (2007, p. 35) afirma:

O éthos é um domínio, um nível, uma estrutura - em resumo, uma dimensão -, mas isso não se limita àquele que fala pessoalmente a um auditório, nem mesmo a um autor que se esconde atrás de um texto e cuja "presença", por esse motivo, afinal, pouco importa. $O$ éthos se apresenta de maneira geral como aquele ou aquela com quem o auditório se identifica, o que tem como resultado conseguir que suas respostas sobre a questão tratada sejam aceitas.

Acreditamos que devemos dar um destaque especial para o trecho final da citação antecedente. Essa aceitação às respostas propostas, de alguma forma, seria o objetivo almejado pelos documentaristas. É claro, e frisaremos isso no próximo e último tópico de nosso artigo, que essa busca por aceitação pode ser mais incisiva, ou pode vir como uma espécie de convite à reflexão. De qualquer forma, a posta em cena, ou seja, a iniciativa na organização de um discurso fílmico documental traz consigo a construção de uma imagem, que pode, ou não, vir a se confirmar, dependendo, também, do éthos prévio ${ }^{15}$ do sujeito-da-câmera. Expliquemos melhor essa questão a partir de uma situação hipotética: suponhamos que um determinado documentarista, em função de declarações em redes sociais, ou por ter se filiado a determinados grupos políticos, seja notabilizado por posições discriminatórias e preconceituosas. Se, por ventura, esse hipotético cineasta resolver construir um documentário voltado para narrar as lutas enfrentadas pela comunidade LGBT, certamente, seu éthos prévio irá interferir, uma vez que o processo de produção imagética está atrelado à necessidade de obter a adesão do público a partir de um determinado ponto de vista transmitido pela produção fílmica. O componente etótico é concernente ao orador (em nosso caso, pensamos no documentarista, no conjunto de sua obra e nos elementos dóxicos que

\footnotetext{
15 De acordo com Amossy (2013, p. 137), o éthos prévio ou éthos pré-discursivo "faz parte da bagagem dóxica dos interlocutores e é necessariamente mobilizado pelo enunciado em situação [nos documentários, esse item lexical situação é problemático, já que o esse gênero se constitui mediante um trabalho de montagem e pós-produção]. [...] No discurso, elabora-se, assim, uma imagem verbal que o leitor [espectador] pode recompor ao reunir um conjunto de elementos frequentemente esparsos e lacunares em uma representação familiar".
} 
EID\&A - Revista Eletrônica de Estudos Integrados em Discurso e Argumentação, Ilhéus, n. 13, jan/jun.2017.

circulam a sua vida). O lógos seria o discurso, ou seja, a estrutura discursiva do documentário. Por sua vez, o pathos, se inscreve na esfera do auditório (espectador). A respeito do lógos, Amossy (2011, p. 19) afirma:

[...] o lógos não se limita aos esquemas de raciocínio subjacentes aos discursos que visam conseguir a adesão do auditório. Ele consiste em um conjunto de meios discursivos que permitem fundar um acordo no sentido amplo do termo, quer se trate de alterar as formas de ver, quer de comunicar, no âmbito dos mesmos valores.

Quais seriam esses conjuntos de meios discursivos? Poderíamos encontrar essa resposta através dos postulados do já discutido edifício retórico. Desde a invenção, ou seja, da formulação de um ponto de vista a ser discursivizado, passando pela disposição, constituída pela montagem, e pela elocução, concernente aos elementos ligados ao plano de expressão, todo esse processo é pertencente ao lógos. Não nos esqueçamos, ainda, de dar a devida importância para a memória - constituída pela heterogeneidade discursiva e pelos elementos dóxicos - e para a ação - processo de enunciação fílmica.

Por fim, para apresentar o pathos, julgamos ser interessante trazer novamente o filósofo Michel Meyer, pois ele apresenta um pertinente ponto de vista para lidar com essa categoria:

Encontrar as questões implicadas no páthos é tirar partido dos valores do auditório, da hierarquia do preferível, que é a sua. É o que o enraivece, o que ele aprecia, o que ele detesta, o que ele despreza, ou contra o que ele se indigna, o que ele deseja, e assim por diante, que fazem do páthos do auditório a dimensão retórica da interlocução (MEYER, 2007, p. 39).

Como não lidamos com postulados relacionados à estética da recepção, o que nos parece adequado é raciocinar a respeito dos efeitos de sentido construídos pelo documentarista. Que estratégias são utilizadas por ele? Como o plano de expressão foi organizado e que tipos de emoções ele pode evocar no espectador? Esse seria o ponto de partida, lembrando novamente que não nos interessamos pelas emoções sentidas, mas pela tentativa de discursivização patêmica. Para ficar em um exemplo simbólico: em Estamira, quando o sujeito-da-câmera Marcos Prado recorre às imagens de arquivo, ou quando ele "lança mão" de uma fotografia granulada, que tipos de emoções ele buscou suscitar? No filme em questão, a fotografia em preto e branco e as imagens de arquivo estabelecem um diálogo emocional com as falas e movimentos da protagonista, captados pela câmera. Quando ela, por exemplo, conta a história de sua primeira desilusão amorosa, a montagem 
EID\&A - Revista Eletrônica de Estudos Integrados em Discurso e Argumentação, Ilhéus, n. 13, jan/jun.2017.

insere uma imagem de arquivo no qual vemos Estamira junto com seu exmarido. Diante disso, a prova do pathos pode ser analisada mediante os elementos fílmicos inseridos pelo sujeito-da-câmera.

\section{Dimensão Argumentativa x Intenção Argumentativa}

Antes de partirmos para uma diferenciação entre os dois conceitos, é pertinente apresentar a conceituação de argumentação, proposta por Ruth Amossy, uma vez que essa pesquisadora problematizou a respeito da dicotomia nomeadora do tópico. Vejamos o que ela nos diz:

A argumentação consiste na utilização da linguagem feita por um sujeito falante em um dispositivo no qual ele deve levar em conta as premissas do alocutário. Tal abordagem reserva um lugar preponderante à doxa sobre a qual o orador se baseia para levar seu auditório aos seus pontos de vista e para construir um acordo sobre o razoável em uma situação que comporta, por definição, várias alternativas (AMOSSY, 2011, p. 16).

Destacamos duas questões concernentes à citação anterior: quando a autora fala de "utilização da linguagem" e na metade final, quando ela postula a necessidade do orador em "levar seu auditório aos seus pontos de vista". A nosso ver, esses dois recortes nos permitem diferenciar a dimensão argumentativa da intenção argumentativa. Expliquemos essa questão, tomando como ponto de partida algumas temáticas passíveis de serem tratadas pelo discurso fílmico documental. O supracitado teórico americano Bill Nichols (2014) estabelece uma tríade na qual os documentaristas, comumente, se propõem a apresentar pontos de vista: identidade social, intimidade sexual e pertença social. A partir disso, o autor aponta alguns assuntos relevantes a serem problematizadas pelos discursos fílmicos:

Ao longo dos caminhos marcados por nossos desejos nessas três direções, encontramos assuntos tão fundamentais como biografia e autobiografia, poder e hierarquia, violência e guerra, economia, nacionalidade, etnicidade, raça, justiça social e mudança social, história e cultura (NICHOLS, 2014, p. 109).

Com todos esses pontos levantados, tratemos, agora, de efetuar a diferenciação entre os dois termos, porém, não podemos desconsiderar que eles se assemelham em uma coisa: a necessidade de apresentar um ponto de vista, buscando, com isso, a adesão. O que muda, evidentemente, é a forma para organizar as ideias. As linhas abaixo, em que utilizaremos documentários 
EID\&A - Revista Eletrônica de Estudos Integrados em Discurso e Argumentação, Ilhéus, n. 13, jan/jun.2017.

brasileiros como estudos de caso, poderão esclarecer melhor o que queremos dissertar.

Nos anos 1960, a partir da Caravana Farkas e de filmes como Garrincha, alegria do povo (1962), de Joaquim Pedro de Andrade; Maioria absoluta (1964), de Leon Hirszman; e A opinião pública (1967), de Arnaldo Jabor; o documentário brasileiro assumiu uma faceta mais engajada politicamente. De certa forma, o estado de coisas vigente no período contribui para esse direcionamento, uma vez que estamos falando de uma década em que o país viveu um regime ditatorial. A partir disso, os filmes eram notadamente inscritos em uma linha de pensamento de viés de esquerda, e os temas tratados, em grande parte, lidavam com a desigualdade social. O que se percebe nesses filmes é um posicionamento explícito e uma necessidade de criar obras que evidenciassem o ponto de vista dos realizadores. Nesse sentido, podemos afirmar que essas produções trazem consigo uma intenção argumentativa. Elas buscam uma mobilização do espectador, utilizando, para tanto, estratégias explicitamente persuasivas.

Em A opinião pública, por exemplo, Jabor adota a classe média como principal alvo de críticas. Para tanto, ele utiliza o recurso da voice over que apresenta essa classe como alienada e preocupada apenas com futilidades. Não obstante, ele conduz entrevistas com jovens que, de fato, parecem estar preocupados apenas com o prazer, ou seja, alheios aos problemas sociais enfrentados pelo país.

A dimensão argumentativa, em contrapartida, se desenvolve de forma mais sutil. Os documentários posicionados nessa categoria buscam apresentar uma realidade, porém, o ponto de vista do documentarista, de certa forma, é tácito. É claro que a montagem e a pós-produção trazem a "voz do cineasta", mas nesses documentários, o espectador é convidado a refletir, sem que haja um direcionamento tão evidenciado. Ruth Amossy (2011, p. 25) afirma que a dimensão argumentativa traz consigo uma "capacidade de guiar o olhar [para] levantar um questionamento para o qual não há necessariamente uma resposta". O olhar é guiado, uma vez que o material foi organizado disposição -, porém, há certo recolhimento do sujeito-da-câmera. Dizendo melhor, há uma retirada estética.

$\mathrm{Na}$ cinematografia brasileira, filmes de dimensão argumentativa são organizados mediante aquilo que o pesquisador brasileiro Fernão Pessoa Ramos (2013) nomeia de ética modesta. Segundo o autor, esse estilo de 
EID\&A - Revista Eletrônica de Estudos Integrados em Discurso e Argumentação, Ilhéus, n. 13, jan/jun.2017.

organizar o discurso fílmico documental, que vigorou no Brasil a partir dos anos 1990, se apresenta mais intimista, trazendo uma diminuição na abrangência da temática a ser tratada. Explicando melhor: os filmes mais marcadamente intencionais, no tocante à argumentatividade, se apresentam, muitas vezes, como manifestos. Eles querem abrir a discussão em um sentido macro, como, por exemplo, o mencionado documentário A Opinião pública que critica a classe média, ou seja, um agente complexo, heterodoxo e abrangente. A dimensão argumentativa, por sua vez, prima em trazer uma realidade mais particularizada. São temáticas como: o cotidiano de uma catadora de lixo - Estamira; a rotina de três irmãs que sofrem de deficiência visual - A pessoa é para o que nasce (2005), de Roberto Berliner; a situação de vida de alguns homossexuais residentes em comunidades - Favela gay (2014), de Rodrigo Felha.

É válido ressaltar que não estamos afirmando que os documentários de dimensão argumentativa são conformistas. Ao contrário, eles proporcionam uma reflexão, sem a necessidade de um explícito direcionamento. $O$ espectador, em muitos desses filmes, é convidado a raciocinar nas situações apresentadas. O ponto de vista do documentarista pode estar implícito, porém, isso não quer dizer que ele não busque a adesão do público. Os documentários sendo, a nosso ver, obras retóricas e argumentativas, em grande parte, possuem a adesão como finalidade por parte de quem os organiza.

\section{Considerações finais}

O que pretendemos com esse artigo foi atestar a retoricidade ontológica ao discurso fílmico documental. Para tanto, realizamos algumas discussões, tomando como pontos de partida pressupostos básicos da retórica. A principal conclusão atingida gira em torno da inerente busca pela adesão almejada pelos sujeitos-da-câmera. No último tópico, priorizamos uma discussão a respeito da organização adotada por determinados discursos fílmicos para transmitir o ponto de vista de seus cineastas. Partimos do princípio de que o gênero documentário sempre carrega marcas de um posicionamento de seus realizadores, o que pode mudar é a gradação, ou seja, a variação da intensidade persuasiva na exposição dos argumentos.

É correto afirmar que o documentário não pode ser pensado como um argumento de autoridade, ou seja, não se deve sacramentar a veracidade de um determinado ponto de vista a partir de sua organização em discurso fílmico. Ao 
EID\&A - Revista Eletrônica de Estudos Integrados em Discurso e Argumentação, Ilhéus, n. 13, jan/jun.2017.

contrário, esse tipo de produção é um recorte subjetivo da realidade. A partir de uma percepção de mundo, direcionada pelos elementos dóxicos circulantes e localizada na esfera da invenção, o cineasta lança mão de estratégias, inscritas na disposição e na elocução, que visam transmitir uma "realidade de mundo" que pode, ou não, encontrar ressonância junto ao espectador.

\section{Referências}

AMOSSY, Ruth. Argumentação e análise do discurso: perspectivas teóricas e recortes disciplinares. Trad. Eduardo Lopes Piris e Moisés Olímpio Ferreira. EID\&A - Revista Eletrônica de Estudos Integrados em Discurso e Argumentação. Ilhéus, n.1, nov. 2011, p. 129-144.

. Contribuição da nova retórica para a AD: o estatuto do lógos nas ciências da linguagem. Trad. Gláucia Muniz Proença Lara e Renata Aiala de Melo. In: EMEDIATO, Wander; LARA, Gláucia Muniz Proença (Org.). Análises do discurso hoje, v.4. Rio de Janeiro: Nova Fronteira, 2011. p. 11-28.

. O ethos na interseção das disciplinas: retórica, pragmática, sociologia dos campos. Trad. Dilson Ferreira da Cruz. In: AMOSSY, Ruth (Org.). Imagens de si no discurso: a construção do ethos. São Paulo: Contexto, 2013. p. 119-144.

ARCANJO, Fábio Ávila. A retórica da performatividade a partir do documentário Estamira. 156f. Dissertação (Mestrado em Estudos Linguísticos - Área: Análise do Texto e do Discurso), Universidade Federal de Minas Gerais, Belo Horizonte, 2017.

AUMONT, Jacques; MARIE, Michel. Dicionário teórico e crítico de cinema. Trad. Eloísa Araújo Ribeiro. 5.ed. Campinas: Papirus, 2012.

BRASIL, André. Quando o antecampo se avizinha: Duas notas sobre engajamento em "A cidade é uma só?". Revista Negativo: Cineclube Beijoca. Brasília, v. 1, n.1, p. 87-100, 2013.

CHARAUDEAU, Patrick. O discurso político. Trad. Fabiana Komesu e Dilson Ferreira da Cruz. 2.ed. São Paulo: Contexto, 2013.

COMOLLI, Jean-Louis. Ver e poder: a inocência perdida: cinema, televisão, ficção, documentário. Trad. Agustin de Tuguy, Oswaldo Teixeira, Rubens Caixeta. Belo Horizonte: Ed.UFMG, 2008.

EKKEHARD, Eggs. Ethos aristotélico, convicção e pragmática moderna. Trad. Dilson Ferreira da Cruz. In: AMOSSY, Ruth (Org.). Imagens de si no discurso: a construção do ethos. São Paulo: Contexto, 2013. p. 29-56.

FIORIN, José Luiz. Argumentação. São Paulo: Contexto, 2015. 
EID\&A - Revista Eletrônica de Estudos Integrados em Discurso e Argumentação, Ilhéus, n. 13, jan/jun.2017.

GRIERSON, John. Flaherty's poetic' Moana, The New York Sun, 8 de fev. In: JACOBS Lewis (Org.). The documentar tradition. 2.ed. New York, London, W.W. Norton \& Company, 1979. p. 25-27.

LUCAS, Meize. Caravana Farkas: Itinerários do documentário brasileiro. São Paulo: Annablume, 2012.

MARTIN, Marcel. A linguagem cinematográfica. Trad. Paulo Neves. São Paulo: Editora Brasiliense, 2013.

MEYER, Michel. Questões de retórica: linguagem, razão e sedução. Trad. Antônio Hall. Lisboa: Edições 70, 2007.

A retórica. Trad. Marly N. Peres. São Paulo: Ática, 2007.

- Prefácio - Aristóteles ou a retórica das paixões. In: ARISTÓTELES. Retórica

das paixões. Trad. Ísis Borges da Fonseca. São Paulo: Martins Fontes, 2000. p. XVII-LI.

NICHOLS, Bill. Introdução ao documentário. Trad. Mônica Saddy Martins. 5.ed. Campinas: Papirus, 2014.

PLANTIN, Christian. Análise e crítica do discurso argumentativo. Trad. Rodrigo dos Santos Mota; Sébastien Giuliano Giancola; Thaise Almeida dos Santos. Rev. Trad. Moisés Olímpio Ferreira; Sérgio Israel Levemfous. In: EID\&A - Revista Eletrônica de Estudos Integrados em Discurso e Argumentação. Ilhéus, n.1, p.17-37, nov. 2011.

RAMOS, Fernão Pessoa. Mas afinal... O que é mesmo documentário? 2.ed. São Paulo: Editora Senac, 2013.

REBOUL, Olivier. Introdução à retórica. Trad. Ivone Castilho Benedetti. 2.ed. São Paulo: Martins Fontes, 2004.

Forma de citação sugerida:

ARCANJO, Fábio Ávila. A argumentação retórica no gênero fílmico documental. EID\&A - Revista Eletrônica de Estudos Integrados em Discurso e Argumentação, Ilhéus, n. 13, p. 1-17, jan/jun.2017.

Recebido em: 06/03/2017

Aprovado em: 15/05/2017 